\title{
To Slinky, with love, part 2
}

\author{
Cindy A. Buckmaster, PhD, CMAR, RLATG
}

Those of you who read this column last month had the pleasure of meeting Slinky, one of the most engaging porcine personalities I have ever known. He came to us as a precious, little pink busybody and grew to about $700 \mathrm{lb}$ of entertaining affection-giant, gentle and smiley. Slinky had his caregivers wrapped around his porky hoof and well trained to attend to his every desire. I told you last month about his 'Julius Ceasar' approach to snack time. That was adorable, but he had several other daily rituals that also endeared him to us. Slinky grew rapidly, and he was trained to walk down the hall to a scale in exchange for 'veggie bites'. It didn't take him long to discover that his caregivers would bring him veggie bites whenever he wanted them if he went and stood on the scale on his own. Imagine a giant pig standing on a scale waiting patiently for someone to appear, like a human Pez dispenser, delivering treats on command! They played this game together every day and it was priceless, but nothing compared with his routine for demanding belly rubs. He would lie down on his side, make eye contact with his caregiver, lift his front leg in the air and hold it there until she got on the floor and rubbed his belly. Nothing else moved, just his eyes and his chubby leg. Massage time was for relaxing, after all! Slinky was probably the bossiest pig on Earth, and he was too cute to deny. I can't describe the loss we felt when he took his last breath. We know he lost his life for our children. We know he is a hero. We were grateful to be with him when it was time for him to leave us. But Slinky took a part of us with him when he left that day. We will live with that missing space in our hearts forever. We lose a lot of animals in our work. Some losses are hard and others rip you to shreds. Slinky's favorite caregiver couldn't look at his empty run for months without crying. That happens sometimes. This was one of those times. I want you to know that Slinky was special. I want you to appreciate what he lost for you. I want you to appreciate what we lost for you. And I want you to honor Slinky's memory with us.

We lose a lot of animals in our work. Some losses are hard
and others rip you to shreds.

Last October, the Beagle Freedom Project (BFP) desecrated Slinky's memory in a toxic social media post. I believe this post was directed at me, although they didn't disclose my name. I gave a talk at the 65th National AALAS Meeting entitled, "Speak Now or Forever Rest in Peace." My central point was that transparency is the "holy grail' of compassionate solutions for animals and people moving forward, and that hiding is a death sentence-for all of us. The managing director of the BFP attended the meeting and was in the audience. I presented my concerns about the BFP's dishonest engagement with our community, and I shared an online post from the managing director that clarified the BFP's true mission to "ban animal testing" before we are realistically prepared to do so. I also shared an image of Slinky.

Later that day the BFP posted on their Facebook page that "last month BFP proudly rescued a perky little piggy from a research laboratory and named her 'Slinky' (on the right). She is happy, pampered, and full of life. The original Slinky sadly we could not save because the researcher who

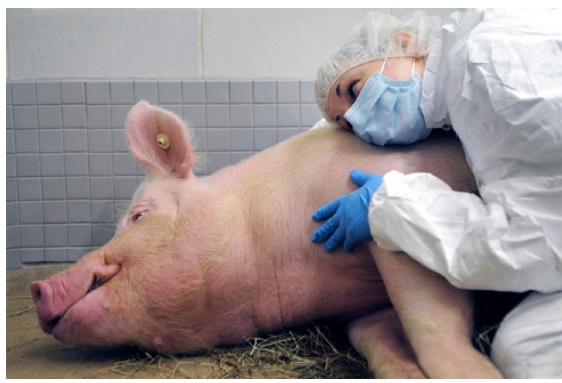

tormented her for years chose to kill her instead of letting a group like BFP give her life. Today that researcher is giving a presentation to other lab workers about how 'bad' BFP is for trying to save the animals they would rather kill. She warns that freeing healthy lab animals will lead to scrutiny and possibly criticism of what they do in these secret labs. Apparently their fragile egos are more important than the lives of other Slinkys. Even though we disagree with animal testing, we hope most researchers don't share this extremist position."

This wickedly fabricated depiction of Slinky's life and my presentation generated some hostile and threatening responses: "Why don't you print the name and phone number of the researcher? ... I agree, plaster her name all over facebook. Maybe she would like to be tortured the way she did poor Slinky.... Bravo BFP, Rock on! Death to Lab researchers that use live animals and then refuse to grant them life and freedom when done.... I would like to see how quickly a lab tech can run from a 5.56 round."

The BFP will not be attending the National AALAS meeting this year. AALAS is a global leader in preparing highly trained, compassionate laboratory animal care professionals. And we fully embrace transparency for education and public awareness, not animal rights extremism. 